\title{
Antimicrobial activities of extracts from leaves and stem-bark of Buddleja salviifolia
}

\author{
${ }^{1, *}$ Pillai, M.K., ${ }^{1}$ Matamane, R.P. and ${ }^{2}$ Mekbib, S.B. \\ ${ }^{1}$ Department of Chemistry and Chemical Technology, Faculty of Science and Technology, National \\ University of Lesotho, Roma Campus, P. O. Roma 180, Kingdom of Lesotho, Southern Africa \\ ${ }^{2}$ Department of Biology, Faculty of Science and Technology, National University of Lesotho, Roma Campus, \\ P. O. Roma 180, Kingdom of Lesotho, Southern Africa
}

\begin{abstract}
Article history:
Received: 12 May 2019

Received in revised form: 13

June 2019

Accepted: 16 June 2019

Available Online: 20 June

2019
\end{abstract}

Keywords:

Buddleja salviifolia,

Buddleja,

Scrophulariaceae,

Antibacterial activity,

Antifungal activity

DOI:

https://doi.org/10.26656/fr.2017.3(6).195

\section{Introduction}

Buddleja salviifolia belongs to the Scrophulariaceae family of the Buddleja genus (Van Wyk and Van Wyk, 1997; Tank et al., 2006; Van Laere et al., 2011). B. salviifolia is also known by other names such as sagewood, wildsaile, saliehout, etc. (Van Wyk and Van Wyk, 1997). Approximately, 150 species are found in the genus Buddleja (Ream, 2006). B. salviifolia is widely distributed in Southern parts of Africa such as South Africa, Lesotho, Zimbabwe, Swaziland, etc. and grows mostly in rocky mountain slopes, dry hillsides, forest margins, coastal and along with the water courses (Palmer, 1977; Ream, 2006). B. salviifolia is a semievergreen plant with greyish appearance (Van Wyk and Van Wyk, 1997) and reaches up to 3 to 8-meter height with many stems at the base (Drummond, 1981). B. salviifolia can be characterized by its small, tubular flowers with enclosing stamens. It has a strong and sweet perfumed smell, especially in the early spring (Palmer,
1977). The leaves of $B$. salviifolia have been used as a food ingredient for improving digestion, anti-emetic, relieve nausea, coughs, colic and constipation (Kose et al., 2015). Additionally, the leaves of B. salviifolia have been used in the traditional medicine to treat TB, syphilis, herpes, cervical cancer, complications associated with pregnancy, etc. (Kose et al., 2015). The leaves of $B$. salviifolia have also been used to treat neurodegenerative conditions and eye infections (Pendota et al., 2014). Our literature search showed that a $20 \%$ methanolic crude extract obtained from the leaves of B. salviifolia and its hexane, dichloromethane, ethyl acetate, and butanol fractions have previously been studied for their antimicrobial activities against Escherichia coli, Staphylococcus aureus, Bacillus subtilis, Klebsiella pneumoniae and Candida albicans (Pendota et al., 2013). Additionally, three pure compounds viz. 4-hydroxyphenyl ethyl vanillate, acteoside, and quercetin have been isolated from the 
ethyl acetate fraction of the leaves extract (Pendota et al., 2013) and these three pure compounds have also been evaluated for their antimicrobial activities (Pendota et al., 2013). However, to the best of our knowledge, hexane, chloroform, ethyl acetate, and $100 \%$ methanolic crude extracts from the leaves and stem-bark of this plant have not been explored well for their antimicrobial studies. Therefore, the aim of the present study was to evaluate the antibacterial and antifungal activities of hexane, chloroform, ethyl acetate and methanol extracts from leaves and stem-bark of $B$. salviifolia against six bacterial isolates viz. E. coli (wild strain), E. coli O157: H7, L. monocytogenes, S. aureus, Serratia marcescens and Pseudomonas aeruginosa and two fungal isolates viz. Penicillium digitatum and C. albicans.

\section{Materials and methods}

\subsection{Plant materials}

Fresh leaves of $B$. salviifolia were collected in August 2018 inside the Roma Campus of National University of Lesotho, Lesotho, Southern Africa. Additionally, a piece of stem-bark was cut from the same plant. Mr. Moretloa Polaki, Lecturer, Department of Biology, Faculty of Science and Technology, National University of Lesotho, Roma Campus, Roma P.O. 180, Lesotho, Southern Africa identified the plant material. A voucher specimen viz. Matamane/BSLS/2018 and Matamane/BSSB/2018 leaves and stem-bark, respectively, were kept separately in the Organic Research Laboratory, Department of Chemistry and Chemical Technology, Faculty of Science and Technology, National University of Lesotho, Roma Campus, Maseru, the Kingdom of Lesotho, Southern Africa.

\subsection{Material processing}

The leaves were allowed to air-dry at room temperature (about $18-24^{\circ} \mathrm{C}$ ) for two weeks. The crushed leaves were ground into powder $(523.86 \mathrm{~g})$ using a dry laboratory blender (Waring Blender, Blender 80119, Model HGB2WT93, 240V AC, 3.5 AMPs, Laboratory and Analytical Supplies). The chopped stem-bark was allowed to air-dry at room temperature (about $18-24^{\circ} \mathrm{C}$ ) for two weeks and then ground into powder (760.46 g) using the same blender.

\subsection{Preparation of plant extracts}

A $100.11 \mathrm{~g}$ of powdered leaves was extracted with hexane for three days at room temperature. The solution was filtered off using a vacuum filter (ATB, Model: 284065-H, Power: 230V 3.0A, 1320/min 50Hz). The solvent was removed in vacuo. The extract was transferred to pre-weighed clean and dry beaker. The same procedure was repeated twice. Finally, the leaves were extracted with hexane at reflux condition for 10 hours. About $1.85 \mathrm{~g}$ of combined hexane extract was obtained after removal of solvent. The same procedure was repeated with chloroform, ethyl acetate and methanol separately. Approximately, 7.48, 8.13 and $14.61 \mathrm{~g}$ of chloroform, ethyl acetate and methanol leave extracts respectively, were obtained from $98.88 \mathrm{~g}$, $100.23 \mathrm{~g}$ and $175.45 \mathrm{~g}$ of powdered leaves. Similarly, using the same procedure, $0.43,1.07,2.18$ and $8.86 \mathrm{~g}$ of hexane, chloroform, ethyl acetate and methanol stembark extracts, respectively, were obtained from $200.09 \mathrm{~g}$, $200.01 \mathrm{~g}, 202.52 \mathrm{~g}$ and $157.82 \mathrm{~g}$ powdered stem-bark.

\subsection{Evaluation of antimicrobial activity}

The antimicrobial activities of various extracts of $B$. salviifolia were evaluated by in vitro hole-plate diffusion method as described in the literature (Manilal et al., 2009; Alghazeer et al., 2012). Solutions of various extracts were prepared separately at a concentration of $100 \mathrm{mg}$ of extract in $1 \mathrm{~mL}$ of DMSO. The solutions were then filtered separately using a $0.20 \mu \mathrm{m}$ filter and then used for both antibacterial and antifungal activities. A volume of $0.1 \mathrm{~mL}$ of the broth culture of each bacterial isolate was spread on the NA (Nutrient Agar) plates separately. Agar wells of size $4.00 \mathrm{~mm}$ height and 6.00 $\mathrm{mm}$ diameter were punched on the agar plate using a sterile cork-borer and filled with $35 \mu \mathrm{L}$ aliquots of the extract. The plates were then incubated at $37^{\circ} \mathrm{C}$ for 24 hours. Tetracycline served as a positive control for $E$. coli (wild strain), E. coli (O157: H7), S. aureus and $L$. monocytogenes. Amoxicillin served as a positive control for $P$. aeruginosa and $S$. marcescens. DMSO served as a negative control. The Petri dishes containing $25 \mathrm{~mL}$ of Potato Dextrose Agar (PDA) were used for the antifungal assay. The agar plate was first spread with 0.1 $\mathrm{mL}$ of the fungi. Cylindrical cavities of size $4.00 \mathrm{~mm}$ height and $6.00 \mathrm{~mm}$ diameter were punched using a sterile cork-borer and filled with the $35 \mu \mathrm{L}$ aliquots of the extract. The plates were incubated at $24^{\circ} \mathrm{C}$ for $48 \mathrm{hrs}$. Miconazole nitrate served as a positive control for $C$. albicans. However, we did not maintain positive control for $P$. digitatum. DMSO served as a negative control. The sensitivity of microorganisms to the various extracts of $B$. salviifolia was determined by measuring the diameter of inhibition zones around the holes of the agar surface. All experiments were performed in duplicate and the results were reported as the average of two experiments. A clear zone $>10 \mathrm{~mm}$ are considered as a positive result (Lima-Filho et al., 2002). Inhibition zones of $<12,12-20$ and $\geq 20 \mathrm{~mm}$ diameter is expressed as weak, moderate and strong activities respectively (Emmanuel et al., 2012; Matela et al., 2018). 
2.5 Determination of minimum inhibitory concentrations (MICs)

The minimum concentration of the sample that is needed to inhibit the growth of the microorganisms is called MIC value (Alghazeer et al., 2012; Alghazeer et al., 2017). The MIC of $<100 \mu \mathrm{g} / \mathrm{mL}, 100$ to $\leq 625 \mu \mathrm{g} /$ $\mathrm{mL}$ and $>625 \mu \mathrm{g} / \mathrm{mL}$ were considered as significantly active, moderately active and weakly active, respectively (Emmanuel et al., 2012; Njimoh et al., 2015; Alghazeer et al., 2017). The MICs of various extracts of $B$. salviifolia were determined as described in the literature (Daud et al., 2005; Alghazeer et al., 2017). Briefly, a stock solution at a concentration of $1000 \mu \mathrm{g} / \mathrm{mL}$ of various extracts of $B$. salviifolia was prepared separately. Two-fold serial dilutions such as $1000,500,250,125$, 62.5 and $31.25 \mu \mathrm{g} / \mathrm{mL}$ were made from these stock solutions. A suspension of the microorganism is prepared at a concentration of one million to two million colony forming units $(\mathrm{CFU}) / \mathrm{mL}$ by means growing the bacterial strain in nutrient broth in an incubator with continuous shaking (Matela et al., 2018). Cylindrical cavities of size $4.00 \mathrm{~mm}$ height and $6.00 \mathrm{~mm}$ diameter were punched on the agar plate using a sterile cork-borer and then filled with the $35 \mu \mathrm{L}$ aliquots of the extract. The plates were then incubated at $37^{\circ} \mathrm{C}$ for $24 \mathrm{hrs}$.

\subsection{Microorganisms}

A total of six bacterial isolates (four Gram-negative bacteria viz. E. coli (wild strain), E. coli O157: H7, S. marcescens and $P$. aeruginosa), (two Gram-positive bacterial isolates viz. L monocytogenes and $S$. aureus) and two fungal isolates viz. P. digitatum and C. albicans were used in this study to evaluate the antimicrobial activities of the various extracts from the leaves and stem -bark of B. salviifolia. All these microorganisms are available at the Department of Biology, National University of Lesotho, Roma, Kingdom of Lesotho, Southern Africa.

\subsection{Statistical analysis}

Data analysis was performed using the SPSS 17.0 statistics program by means of two-way analysis of variance. The differences were considered statistically significant when $\mathrm{p} \leq 0.05$.

\section{Results and discussion}

The antibacterial activity of various extracts of $B$. salviifolia is summarized in Table 1. BSHXLS, BSCHLS, BSEALS, BSMELS are B. salviifolia hexane leaves extract, chloroform leaves extract, ethyl acetate leaves extract and methanol leaves extract, respectively. BSHXSB, BSCHSB, BSEASB and BSMESB are $B$. salviifolia hexane stem-bark extract, chloroform stem- bark extract, ethyl acetate stem-bark extract and methanol stem-bark extract, respectively. BSHXLS, BSCHLS, BSEALS, BSMELS, BSHXLS, BSCHSB, BSEALS and BSMESB exhibited inhibition zones of $10.0 \pm 2.8, \quad 14.0 \pm 1.4, \quad 15.0 \pm 4.2, \quad 13.0 \pm 1.4, \quad 13.5 \pm 3.5$, $16.0 \pm 0.7, \quad 10.5 \pm 0.7$ and $12.0 \pm 3.5 \mathrm{~mm}$ respectively against $E$. coli (wild strain). This result showed that BSCHLS, BSEALS, BSMELS, BSHXSB, BSCHSB and BSMESB showed a moderate activity and the remaining extracts, BSHXLS and BSEASB, showed a weak activity against $E$. coli (wild strain). The positive control, tetracycline, showed an inhibition zone of $19.5 \pm 3.5 \mathrm{~mm}$. BSHXLS, BSCHLS, BSEALS, BSMELS, BSHXSB, BSCHSB and BSEASB exhibited inhibition zones of $14.0 \pm 0.0,11.0 \pm 1.4,13.0 \pm 1.4,7.0 \pm 1.4,8.0 \pm 2.0,13.0 \pm 4.2$ and $11.0 \pm 2.8 \mathrm{~mm}$ respectively, against $E$. coli $(\mathrm{O} 157$ : H7). This result showed that BSHXSB, BSCHLS, BSEASB and BSMELS are weakly active. The BSHXLS, BSEALS and BSCHSB are moderately active. However, BSMESB did not exhibit any visible inhibition zone. The positive control, tetracycline, showed an inhibition zone of $22.5 \pm 2.1 \mathrm{~mm}$. BSHXLS, BSCHLS, BSEALS, BSMELS, BSHXSB, BSCHSB, BSEASB and BSMESB exhibited inhibition zones of $16.5 \pm 0.7$,

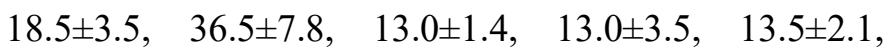
$13.0 \pm 0.0$ and $15.5 \pm 0.7 \mathrm{~mm}$, respectively, against $L$. monocytogenes. This result showed that BSEALS is strongly active while the other extracts, BSHXLS, BSCHLS, BSMELS, BSHXSB, BSCHSB, BSEASB and BSMESB are moderately active. The positive control, tetracycline showed an inhibition zone of $22.5 \pm 0.7 \mathrm{~mm}$. BSHXLS, BSCHLS, BSEALS, BSHXSB, BSCHSB, BSEASB and BSMESB exhibited inhibition zones of $16.0 \pm 2.8,14.0 \pm 0.0,13.0 \pm 1.4,16.0 \pm 2.8,14.0 \pm 1.4$ and $15.5 \pm 2.1 \mathrm{~mm}$ respectively, against $S$. aureus. Therefore, BSHXLS, BSCHLS, BSEALS, BSHXSB, BSCHSB, BSEASB and BSMESB are moderately active. BSMELS showed no visible zone of inhibition and therefore, it is inactive against $S$. aureus. The positive control, tetracycline, showed an inhibition zone of $31.5 \pm 0.7 \mathrm{~mm}$. BSHXLS, BSCHLS, BSEALS, BSMELS, BSHXSB, BSCHSB, BSEASB and BSMESB showed inhibition zones of $19.0 \pm 1.4, \quad 11.0 \pm 4.2, \quad 13.5 \pm 0.7, \quad 14.0 \pm 2.8$, $10.5 \pm 2.1, \quad 11.0 \pm 1.4, \quad 9.0 \pm 1.4$ and $7.5 \pm 0.7 \mathrm{~mm}$, respectively, against $S$. marcescens. This result showed that BSCHLS, BSMESB, BSCHSB, BSEASB and BSHXSB exhibited weak activity while the rest of the extracts, BSHXLS, BSEALS and BSMELS exhibited moderate activity. The positive control, amoxicillin, showed an inhibition zone of $9.0 \pm 0.0 \mathrm{~mm}$. BSHXLS, BSCHLS, BSEALS, BSMELS, BSHXSB, BSCHSB, BSEASB and BSMESB showed inhibition zones of $\begin{array}{lll}17.5 \pm 4.9, & 20.0 \pm 0.0, \quad 16.5 \pm 0.7, \quad 12.5 \pm 2.1, & 16.0 \pm 2.8,\end{array}$ $14.5 \pm 2.1, \quad 11.0 \pm 4.2$ and $16.0 \pm 0.0 \mathrm{~mm}$, respectively, 
Table 1. Inhibitory effect of hexane, chloroform, ethyl acetate and methanolic extracts from leaves and stem-bark of $B$. salviifolia against bacterial and fungal isolates.

\begin{tabular}{|c|c|c|c|c|c|c|c|c|}
\hline \multirow[b]{2}{*}{ Extracts } & \multicolumn{8}{|c|}{ Microorganisms/Inhibition zones (mm) } \\
\hline & $\begin{array}{c}\text { E. coli } \\
\text { (wild strain) }\end{array}$ & $\begin{array}{c}\text { E. coli } \\
(\mathrm{O} 157: \mathrm{H} 7)\end{array}$ & L. monocytogenes & S. aureus & S. marcescens & P. aeruginosa & P. digitatum & C. albicans \\
\hline$\overline{\text { BSHXLS }}$ & $10.0 \pm 2.8$ & $14.0 \pm 0.0$ & $16.5 \pm 0.7$ & $16.0 \pm 2.8$ & $19.0 \pm 1.4$ & $17.5 \pm 4.9$ & $14.0 \pm 0.0$ & $12.0 \pm 2.8$ \\
\hline BSCHLS & $14.0 \pm 1.4$ & $11.0 \pm 1.4$ & $18.5 \pm 3.5$ & $14.0 \pm 0.0$ & $11.0 \pm 4.2$ & $20.0 \pm 0.0$ & $12.5 \pm 0.7$ & $12.5 \pm 2.1$ \\
\hline BSEALS & $15.0 \pm 4.2$ & $13.0 \pm 1.4$ & $36.5 \pm 7.8$ & $13.0 \pm 1.4$ & $13.5 \pm 0.7$ & $16.5 \pm 0.7$ & $11.5 \pm 2.1$ & $13.5 \pm 2.1$ \\
\hline BSMELS & $13.0 \pm 1.4$ & $7.0 \pm 1.4$ & $13.0 \pm 1.4$ & - & $14.0 \pm 2.8$ & $12.5 \pm 2.1$ & $9.0 \pm 1.4$ & $18.0 \pm 5.7$ \\
\hline BSHXSB & $13.5 \pm 3.5$ & $8.0 \pm 2.8$ & $13.0 \pm 3.5$ & $16.0 \pm 2.8$ & $10.5 \pm 2.1$ & $16.0 \pm 2.8$ & $15.5 \pm 3.5$ & $14.0 \pm 0.0$ \\
\hline BSCHSB & $16.0 \pm 2.8$ & $13.0 \pm 4.2$ & $13.5 \pm 2.1$ & $12.0 \pm 2.8$ & $11.0 \pm 1.4$ & $14.5 \pm 2.1$ & $12.5 \pm 4.5$ & $9.5 \pm 3.5$ \\
\hline BSEASB & $10.5 \pm 0.7$ & $11.0 \pm 2.8$ & $13.0 \pm 0.0$ & $14.0 \pm 1.4$ & $9.0 \pm 1.4$ & $11.0 \pm 4.2$ & $14.0 \pm 2.8$ & $12.0 \pm 4.2$ \\
\hline BSMESB & $12.0 \pm 3.5$ & - & $15.5 \pm 0.7$ & $15.5 \pm 2.1$ & $7.5 \pm 0.7$ & $16.0 \pm 0.0$ & $7.0 \pm 0.0$ & $12.0 \pm 5.6$ \\
\hline Positive controls & $19.5 \pm 3.5$ & $22.5 \pm 2.1$ & $31.5 \pm 0.7$ & $22.5 \pm 0.7$ & $22.5 \pm 2.1$ & $9.0 \pm 0.0$ & N/A & $25.8 \pm 1.8$ \\
\hline
\end{tabular}

$\mathrm{BSHXLS}=$ B. salviifolia hexane leaves extract, BSCHLS $=$ B. salviifolia chloroform leaves extract, BSEALS $=$ B. salviifolia ethyl acetate leaves extracts, BSMELS $=B$. salviifolia methanol leaves extract, BSHXSB $=B$. salviifolia hexane stem-bark extract, $\mathrm{BSCHSB}=$ B. salviifolia chloroform stem-bark extract, BSEASB $=$ B. salviifolia ethyl acetate stem-bark extract, BSMESB = B. salviifolia methanol stem-bark extract. Tetracycline served as a positive control for E. coli, E. coli O157: H7, L. monocytogenes and $S$. aureus. Amoxicillin served as a positive control for $S$. marcescens and $P$. aeruginosa. Miconazole nitrate served as a positive control for $C$. albicans. DMSO served as a negative control. $(-)=$ No visible inhibition zone is observed. N/A $=$ Not applicable.

against $P$. aeruginosa. This result showed that BSEASB is weakly active and the other extracts, BSHXLS, BSCHLS, BSEALS, BSMELS, BSHXSB, BSCHSB and BSMESB are moderately active. The positive control, amoxicillin, showed an inhibition zone of $22.5 \pm 2.1 \mathrm{~mm}$. The antifungal activity of various extracts of $B$. salviifolia is also summarized in Table 1. BSHXLS, BSCHLS, BSEALS, BSMELS, BSHXSB, BSCHSB, BSEASB and BSMESB exhibited inhibition zones of

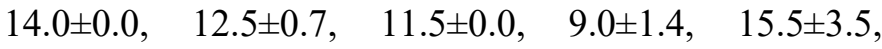
$12.5 \pm 4.5, \quad 14.0 \pm 2.8$ and $7.0 \pm 0.0 \mathrm{~mm}$, respectively, against $P$. digitatum. These results showed that BSMELS, BSEALS and BSMESB are weakly active while the rest, BSHXLS, BSCHLS, BSHXSB, BSCHSB and BSEASB, are moderately active against $P$. digitatum. BSHXLS, BSCHLS, BSEALS, BSMELS, BSHXSB, BSCHSB, BSEASB and BSMESB exhibited inhibition zones of $12.0 \pm 2.8,12.5 \pm 2.1, \quad 13.5 \pm 2.1$, $18.0 \pm 5.7,14.0 \pm 0.0,9.5 \pm 3.5,12.0 \pm 4.2$ and $12.0 \pm 5.6 \mathrm{~mm}$ respectively, against $C$. albicans. This result indicated that BSCHSB exhibited weak activity while the other extracts, BSHXLS, BSCHLS, BSEALS, BSMELS, BSHXLS, BSEASB and BSMESB exhibited moderate activity. The positive control, miconazole nitrate showed an inhibition zone of $25.8 \pm 1.8 \mathrm{~mm}$. The minimum inhibition concentrations (MICs) of various extracts of $B$. salviifolia are summarized in Table 2. The MIC value of BSMELS, BSHXSB and BSMESB was found to be with of $62.5 \mu \mathrm{g} / \mathrm{mL}$ for each extract against $E$. coli (wild strain) while BSHXLS, BSCHLS, BSEALS, BSCHSB and BSEASB exhibited a moderate activity with MIC values of $500,125,125,250$ and $125 \mu \mathrm{g} / \mathrm{mL}$, respectively, against the same bacterial isolates. The MIC value of BSMELS, BSCHSB and BSEASB was found to be 62.5 $\mu \mathrm{g} / \mathrm{mL}$ for each extract against E. coli (O157: H7). However, the MIC values of BSHXLS, BSCHLS, BSEALS, BSHXSB and BSMESB were found to be $125,500,500125$ and $>1000 \mu \mathrm{g} / \mathrm{mL}$, respectively, against $E$. coli H0157. The MIC value of BSHXLS and BSCHLS was determined to be $>1000 \mu \mathrm{g} / \mathrm{mL}$ for each extract against $L$. monocytogenes while the MIC value of BSEALS, BSMELS, BSEASB and BSMESB was determined to be $<31.25,62.5$ and $62.5 \mu \mathrm{g} / \mathrm{mL}$, respectively, and the $\mathrm{MIC}$ value of $\mathrm{BSHXSB}$ and BSCHSB were found to be 125 and $250 \mu \mathrm{g} / \mathrm{mL}$ respectively against the same bacterial isolates. The $\mathrm{MIC}$ value of BSCHLS and BSEALS was found to be $250 \mu \mathrm{g} /$ $\mathrm{mL}$ for each, against $S$. aureus. The MIC value of BSMELS, BSHXSB, BSCHSB, BSEASB and BSMESB was found to be $500 \mu \mathrm{g} / \mathrm{mL}$ for each and the MIC value of BSHXLS was determined to be $>1000 \mu \mathrm{g} / \mathrm{mL}$ against the same bacterial isolates. The MIC value of BSHXLS, BSCHLS, BSEALS and BSMELS was found to be $250 \mu \mathrm{g} / \mathrm{mL}$ for each, against $S$. marcescens. BSMELS, BSHXSB and BSEASB showed MIC values of $125 \mu \mathrm{g} /$ $\mathrm{mL}$ for each and BSCHSB showed a MIC value of $>1000 \mu \mathrm{g} / \mathrm{mL}$ against $S$. marcescens. The MIC value of BSCHLS, BSMELS, BSHXSB and BSEASB was found to be $62.5 \mu \mathrm{g} / \mathrm{mL}$ for each against $P$. aeruginosa while BSHXLS, BSEALS, BSCHSB and BSMESB exhibited MIC values of $250,125,125$ and $250 \mu \mathrm{g} / \mathrm{mL}$, respectively, against the same bacterial isolates. The MIC value of BSEALS, BSHXSB, BSCHSB and BSMESB was found to be $62.5,<31.25,<31.25$ and 62.5 $\mu \mathrm{g} / \mathrm{mL}$, respectively against $P$. digitatum while the $\mathrm{MIC}$ value for BSHXLS, BSMELS and BSEASB were found to be 500,500 and $250 \mu \mathrm{g} / \mathrm{mL}$, respectively, and BSCHLS exhibited an MIC of $>1000 \mu \mathrm{g} / \mathrm{mL}$ against this 
Table 2. The minimum inhibitory concentrations (MICs) of hexane, chloroform, ethyl acetate and methanolic extracts of leaves and stem-barks of $B$. salviifolia extracts against bacterial and fungal isolates.

\begin{tabular}{|c|c|c|c|c|c|c|c|c|}
\hline \multirow[b]{2}{*}{ Extracts } & \multicolumn{8}{|c|}{ Microorganisms/Minimum inhibitory concentrations $(\mu \mathrm{g} / \mathrm{mL})$} \\
\hline & $\begin{array}{c}E . \text { coli } \\
\text { (wild strain) }\end{array}$ & $\begin{array}{c}\text { E. coli } \\
\text { (O157: H7) }\end{array}$ & L. monocytogenes & S. aureus & S. marcescens & P. aeruginosa & P. digitatum & C. albicans \\
\hline$\overline{\text { BSHXLS }}$ & 500 & 125 & $>1000$ & $>1000$ & 250 & 250 & 500 & 125 \\
\hline BSCHLS & 125 & 500 & $>1000$ & 250 & 250 & 62.5 & $>1000$ & 62.5 \\
\hline BSEALS & 125 & 500 & $<31.25$ & 250 & 250 & 125 & 62.5 & 62.5 \\
\hline BSMELS & 62.5 & 62.5 & 62.5 & 500 & 125 & 62.5 & 500 & 62.5 \\
\hline BSHXSB & 62.5 & 125 & 125 & 500 & 125 & 62.5 & $<31.25$ & 62.5 \\
\hline BSCHSB & 250 & $<31.25$ & 250 & 500 & $>1000$ & 125 & $<31.25$ & $<31.25$ \\
\hline BSEASB & 125 & 62.5 & 62.5 & 500 & 125 & 62.5 & 250 & 125 \\
\hline BSMESB & 62.5 & $>1000$ & $<31.25$ & 500 & 250 & 250 & 62.5 & 62.5 \\
\hline
\end{tabular}

$\mathrm{BSHXLS}=$ B. salviifolia hexane leaves extract, BSCHLS $=$ B. salviifolia chloroform leaves extract, BSEALS $=$ B. salviifolia ethyl acetate leaves extracts, BSMELS $=B$. salviifolia methanol leaves extract, BSHXSB $=$ B. salviifolia hexane stem-bark extract, $\mathrm{BSCHSB}=$ B. salviifolia chloroform stem-bark extract, BSEASB $=$ B. salviifolia ethyl acetate stem-bark extract, $\mathrm{BSMESB}=$ B. salviifolia methanol stem-bark extract.

fungal isolates. The MIC value for BSCHLS, BSEALS, BSMELS, BSHXSB and BSMESB were found to be $62.5 \mu \mathrm{g} / \mathrm{mL}$ for each against $C$. albicans while BSCHSB showed a MIC of $31.25 \mu \mathrm{g} / \mathrm{mL}$. However, the MIC value for extract BSHXLS and BSEASB were found to be 125 $\mu \mathrm{g} / \mathrm{mL}$ for each against this fungal isolate.

Pendota et al. (2013) obtained a 20\% methanolic crude extract from the leaves of $B$. salviifolia. Additionally, hexane, dichloromethane, ethyl acetate and butanol fractions were also obtained from this crude extract. The crude extract and these four fractions were screened for their MIC values against four bacterial isolates viz. E. coli, S. aureus, B. subtilis and $K$. pneumoniae and one fungal isolate, $C$. albicans (Pendota et al., 2013). They showed MIC values ranging from 390 $-1560 \mu \mathrm{g} / \mathrm{mL}$ against these microorganisms. The MIC values of crude extract and hexane, dichloromethane, ethyl acetate and butanol fractions were found to be 6250.0, 780.0, 1560.0, 1560.0 and $1560.0 \mu \mathrm{g} / \mathrm{mL}$, respectively, against $E$. coli. The microorganisms $E$. coli is common to our study also. However, we found that the MIC value of methanolic leave extract as $62.5 \mu \mathrm{g} / \mathrm{mL}$. The low MIC value in our study may be due to more extractive power of $100 \%$ methanol relative to $20 \%$ methanol. The MIC values of crude extract, hexane, dichloromethane, ethyl acetate and butanol fractions were found to be $3125.0,1560.0,780.0,390.0$ and $3125.0 \mu \mathrm{g} / \mathrm{mL}$, respectively, against $S$. aureus. The microorganisms $S$. aureus also is common to our study. However, we found that the MIC value of methanolic leave extract as $500 \mu \mathrm{g} / \mathrm{mL}$. This is again due to more extractive power of methanol relative to $20 \%$ methanol. The MIC value for crude extract, hexane and dichloromethane fractions were determined to be 3125.0 $\mu \mathrm{g} / \mathrm{mL}$ for each against $B$. subtilis. The ethyl acetate and butanol fractions showed MIC values of 780.0 and $1560.0 \mu \mathrm{g} / \mathrm{mL}$, respectively, against B. subtilis. The MIC values of crude extract and hexane, dichloromethane, ethyl acetate and butanol fractions were found to be $6250.0,1560.0,1560.0,3125.0$ and $3125.0 \mu \mathrm{g} / \mathrm{mL}$ respectively, against $K$. pneumoniae.

Additionally, three pure compounds viz. 4hydroxyphenyl ethyl vanillate, acteoside and quercetin have been isolated from the ethyl acetate fraction and were evaluated for their antibacterial and antifungal activities against the above microbes (Pendota et al., 2013). The MIC value of 4-hydroxyphenyl ethyl vanillate, acteoside and quercetin were found to be 125.0 $\mu \mathrm{g} / \mathrm{mL}$ for each, against viz. E. coli. The MIC values for 4-hydroxyphenyl ethyl vanillate, acteoside and quercetin were determined to be 250.0, 62.5 and $250.0 \mu \mathrm{g} / \mathrm{mL}$, respectively, against $S$. aureus (Pendota et al., 2013). The MIC values of 4-hydroxyphenyl ethyl vanillate, acteoside and quercetin were found to be 125.0, 125.0 and $250.0 \mu \mathrm{g} / \mathrm{mL}$. respectively, against B. subtilis. On the other hand, 4-hydroxyphenyl ethyl vanillate and acteoside exhibited a MIC value of $62.5 \mu \mathrm{g} / \mathrm{mL}$ for each and quercetin showed a MIC value of $125.0 \mu \mathrm{g} / \mathrm{mL}$ against K. pneumonia (Pendota et al., 2013).

Against $C$. albicans, the MIC values of crude extract, hexane, dichloromethane, ethyl acetate and butanol fractions were reported to be $1560.0,390.0,390.0,780.0$ and $1560.0 \mu \mathrm{g} / \mathrm{mL}$ respectively (Pendota et al., 2013). The MIC values of 4-hydroxyphenyl ethyl vanillate, acteoside and quercetin were found to be 250.0, 250.0 and $125.0 \mu \mathrm{g} / \mathrm{mL}$, respectively, against the same fungal isolates, $C$. albicans. In our study, the MIC value of methanolic extract was found to be $62.5 \mu \mathrm{g} / \mathrm{mL}$. The minimum fungicidal concentration (MFC) of crude extract, hexane, dichloromethane, ethyl acetate and butanol fractions have been reported to be 3125.0, 390.0, $390.0,1560.0$ and $1250.0 \mu \mathrm{g} / \mathrm{mL}$, respectively, against C. albicans. The MFC of 4-hydroxyphenyl ethyl 
vanillate, acteoside and quercetin were found to be $250.0 \mu \mathrm{g} / \mathrm{mL}$ for each, against C. albicans. (Pendota et al., 2013).

As such, the report from Pendota et al. (2013) has been limited only to MIC and MFC values of a $20 \%$ methanolic crude extract from the leaves of $B$. salviifolia and its hexane, dichloromethane, ethyl acetate and butanol fractions. They used four bacterial and one fungal isolate for their study. Additionally, the MIC and MFC values of three pure compounds viz. 4hydroxyphenyl ethyl vanillate, acteoside and quercetin were also evaluated against these four bacterial and one fungal isolate (Pendota et al., 2013). However, in our study, we discussed not only MIC values but also the exact inhibitory effects of eight extracts (four extracts from leaves and the other four from stem-bark) against six bacterial and two fungal isolates.

It has been reported that B. subtilis, S. aureus, E. coli, $K$. pneumoniae, $C$. albicans etc. are responsible for some common ocular infections (Pendota et al., 2013). For example, $E$. coli is responsible for ocular inflammations such as keratitis, blepharitis and conjunctivitis (Bruiser and Burd, 1996). Some Bacillus spp. are responsible for a severe eye interior inflammation with $70 \%$ vision loss after trauma and/or surgery infection (David et al., 1994). In South Africa, leaves extract of $B$. salviifolia has been used to treat eye infections (Pendota et al., 2014). This may be due to the fact that $B$. salviifolia might have contained antibacterial metabolites against E. coli, Bacillus spp. etc. El-Ganiny et al. (2017) reported that extracts from B. salviifolia exhibited a significant biofilm inhibition and also eradicated preformed biofilm. Additionally, B. salviifolia have been showing a variety of other bioactivities such as anti-hypersensitive, analgesic, immunosuppressive, antitumor activities etc. (Herbert et al., 1991).

\section{Conclusion}

We evaluated antibacterial and antifungal activities of hexane, chloroform, ethyl acetate, methanol extracts from leaves and stem-bark of B. salviifolia. Gramnegative bacteria such as $E$. coli (wild strain), E. coli O157: H7, S. marcescens and P. aeruginosa, Grampositive bacteria such as $L$. monocytogenes and $S$. aureus and two fungal isolates viz. P. digitatum and C. albicans were used in this study. All extracts exhibited antimicrobial activity with inhibition zones ranging from $7.0 \pm 1.4$ to $36.5 \pm 7.8 \mathrm{~mm}$ against bacterial and $7.0 \pm 0.0$ to $22.0 \pm 1.4 \mathrm{~mm}$ against fungal isolates. Additionally, all these extracts were also evaluated for their minimum inhibitory concentrations (MICs) and were found to be in the range of $<31.25 \mu \mathrm{g} / \mathrm{mL}$ to $>1000 \mu \mathrm{g} / \mathrm{mL}$ against both bacterial and fungal isolates. To conclude, B. salviifolia exhibited promising antimicrobial activities. $B$. salviifolia has been used as a food ingredient. In traditional medicine, the leaves of $B$. salviifolia have been used to treat eye infections and neurodegenerative conditions. Therefore, further studies on various parts of this pant will be useful to commercialize products.

\section{Conflict of Interest}

The authors declare no conflict of interest.

\section{Acknowledgements}

The authors would like to thank the National University of Lesotho for its support.

\section{References}

Alghazeer, R., El-Saltanil, H., Saleh, N., Al-Najjar, A and Hebail, F. (2012). Antioxidant and antimicrobial properties of five medicinal Libyan plants extracts. Natural Science, 4, 324-335. https:// doi.org/10.4236/ns.2012.45045

Alghazeer, R., Elmansori, A., Sidati, M. and Gammoudi, F. (2017). In vitro antibacterial of flavonoid extracts of two selected Libyan Algae against multi-drug resistant bacteria isolated from food products. Journal of Biosciences and Medicine, 5, 26-48. https://doi.org/10.4236/jbm.2017.51003

Bruiser, J.H. and Burd, E.M. (1996). Principles of Diagnostic Ocular Microbiology. Infections of the eye. $2^{\text {nd }}$ Ed., p. 67-77. Boston, USA: Little Brown Company.

David, D.B., Kirkby, G. B. and Noble, B.A. (1994). Bacillus cereus endophthalmitis. British Journal of Ophthalmology, 78, 577-580. https:// doi.org/10.1136/bjo.78.7.577

Daud, A., Gallo, A. and Sanchez, A. (2005). Antibacterial properties of Phrygilanthus acutifolius. Journal of Ethnopharmacology, 99(2), 193-195. https://doi.org/10.1016/j.jep.2005.01.043

Drummond, R.B. (1981). Trees of Southern Africa., p. 778 -779. Cape Town: Tien Wah Press (Pty) Ltd.

El-Ganiny, A.M., Shaker, G.H., Aboelazm, A.A. and ElDash, H.A. (2017). Prevention of bacterial biofilm formation on soft contact lenses using natural compounds. Journal of Ophthalmic Inflammation and Infection, 7, 1-7. https://doi.org/10.1186/s12348017-0129-0

Emmanuel, M.T., Anatole, C.P. and Veronique, P.B. (2012). Investigations of antimicrobial activity of some Cameroonian medicinal plant extracts against bacteria and yeast with gastrointestinal relevance. 
Journal of Ethnopharmacology, 142(1), 265-273. https://doi.org/10.1016/j.jep.2012.05.005

Herbert, J.M., Maffrand, J.P., Taoubi, K., Augerean, J.M., Fouraste, I. and Gleye, J. (1991). Verbascoside isolated from Lantana camara, an inhibitor of protein kinanase C. Journal of Natural Products, 54, 1595-1600. https://doi.org/10.1021/np50078a016

Kose, L.S., Moteetee, A. and Van Vuuren, S. (2015). Ethnobotanical survey of medicinal plants used in the Maseru district of Lesotho. Journal of Ethnopharmacology, 170, 184-200. https:// doi.org/10.1016/j.jep.2015.04.047

Lima-Filho, M., Carvalho, U. and Freitas, M. (2002). Antibacterial activity of extracts of six Macroalgae from the Northeastern Brazilian Coast. Brazilian Journal of Microbiology, 33, 311-313. https:// doi.org/10.1590/S1517-83822002000400006

Manilal, A., Sujith, S., Kiran, G.S., Seivin, J., Shakir, C., Gandhimathi, R. and Panokkar, M.V.N. (2009). Biopotentials of seaweeds collected from southwest coast of India. Journal of Marine Science and Technology, 17, 67-73.

Matela, K.S., Mekbib, S.B. and Pillai, M.K. (2018). Antimicrobial activities of extracts from Gleditsia triacanthos L. and Schinus molle L. Pharmacology Online, 2, 85-92.

Njimoh, D.L., Assob, J.C.N., Mokake, S.E., Nyhalah, D.J., Yinda, C.K. and Sandjon, B. (2015). Antimicrobial activities of a plethora of medicinal plant extracts and hydrolates against human pathogens and their potential to reverse antibiotic resistance. International Journal of Microbiology, 2015, 1-15. https://doi.org/10.1155/2015/547156

Palmer, E. (1977). A Field Guide to The Trees of Southern Africa. p. 274-275. Great Britain, Glasgow, UK: William Collins Sons and Co Ltd

Pendota, S.C., Aderogba, M.A., Ndlhala, A.R. and Van Staden, J. (2013). Antimicrobial and acetylcholinesterase inhibitory activities of Buddleja salviifolia (L.) Lam. leaf extracts and isolated compounds. Journal of Ethnopharmacology, 148(2), 515-520. https://doi.org/10.1016/j.jep.2013.04.047

Pendota, S.C., Ndhlala, A.R., Aremu, A.O., Aderogba, M.A. and Van Staden, J. (2014). Anti-inflammatory, antioxidant and in silico (i) studies of Buddleja salviifolia (L.) Lam leaf constituents. Journal of Ethnopharmacology, 93, 79-85. https:// doi.org/10.1016/j.sajb.2014.03.012

Ream, J. (2006). Production and invasion of Butterfly Bush (Buddleja davidii) in Oregon., p. 6. Oregon, USA: Oregon State University.

Tank, D.C., Beardsley, P.M. and Kelcher, S.A. (2006).
Olmsted RG. Review of the systematics of Scrophulariaceae S.J. and their current disposition. Australian Systematic Botany, 19(4), 29-307. https:// doi.org/10.1071/SB05009

Van Laere, K., Van Huylenbroeck, J. and Van Bockstaele, E. (2011). Introgression of yellow flower colour in Buddleja davidii by means of polyploidisation and interspecific hybridization. Horticulture Science, 38(3), 96-103. https:// doi.org/10.17221/61/2011-HORTSCI

Van Wyk, B. and Van Wyk, P. (1997) Field guide to Tress of Southern Africa featuring more than 1000 species., p. 258-259. Cape Town: Struik Publishers. 